\title{
Determining the Honduran Basic Food Basket: A Mathematical Approach
}

\author{
Daniel Montenegro, M. Sc ${ }^{1}$, Luis Barahona, Eng. ${ }^{1}$ \\ ${ }^{1}$ Universidad Tecnológica Centroamericana (UNITEC), Facultad de Ingeniería, Departamento de Ingeniería Industrial y de \\ Sistemas, Tegucigalpa, Honduras, 11101, daniel.guerrero@unitec.edu.hn, fernandobarahona@unitec.edu
}

\begin{abstract}
Honduras is a country in Central America with both a high poverty and underemployment rate. An essential basic food basket exists and consists of 30 food items that stands at an average of \$176.01, nevertheless it was not established considering nutritional requirements. Binary linear programming was utilized to determine a basic food basket that could both fulfill this requirement while doing so with the least possible cost. Two optimization models were created with different constraints to evaluate which offered a better solution both in terms of cost and food item variety. A family of 4 people was considered for the study and 6 scenarios were tested for each of the models with 3 sets of repetitions of food items per month allowed. All scenarios obtained an optimal solution that complied with the constraints given. Scenario 2 which consists of a teen male, teen female, adult male and pregnant female was used to determine the BFB since it was the scenario that required the most amount of nutrients and portions of the diverse food groups. Final basic food basket contained 66 items and had a total cost of \$235.86; item variety increased more than double but cost also increased as a side effect.

Keywords-Research Operations; linear programming; optimization; nutritional requirements
\end{abstract}

\section{INTRODUCTION}

Honduras is a country located in Central America; in 2018 it had a population of $9,023,838$ people with $61.85 \%$ of households living in poverty and $38.72 \%$ of these living in extreme poverty [1]. The minimum wage in the country varies according to economic sector and number of employees and stands at an average of $\$ 407.21$ [2]. Nevertheless, the rate of visible and invisible underemployment amassed to $62.82 \%$ by 2018 [1]. Underemployment can be referred as involuntary part-time employment and though it is less financially detrimental to people than unemployment it's still affects the individuals earning potential and even retirement income availability [3]. A key aspect that can be considered of underemployment is loss of income by an individual by working less hours or being underpaid according to a set skill set and experience [4].

The WFP has found that poverty in Honduras is the root of the chronic food insecurity in the country [5]. It can even be as high as $48.5 \%$ in some rural areas; and, on the other side of the spectrum, overweight and obesity are also increasing in adults with $46 \%$ of all people above age 15 being overweight or obese [6]. This has a direct relation with not having an adequate diet or consuming food items that have high caloric intake but don't fulfill nutritional requirements.

Digital Object Identifier (DOI)

http://dx.doi.org/10.18687/LACCEI2020.1.1.142

ISBN: 978-958-52071-4-1 ISSN: 2414-6390
The Basic Food Basket (BFB) has been defined in part as the necessary goods to meet nutritional needs of a population and it is also used to determine the extreme poverty line in a country [7]. Another important aspect that the BFB has to take into account is its composition because it has to reflect the eating patterns of the country's population; it's worth noting that it can be used to define priorities and policies pertaining to employment and wage distribution amongst others [8]. Honduras has what has been called an essential BFB which consists of 30 food items that have been deemed to represent the consumption pattern of the poorest families in the country and stands at an average \$176.01[9]. This was determined entirely from an economic point of view without considering the nutritional needs of the population.

When considering a healthy woman in reproductive age and attempting to determine the best combination of these 30 items using an optimization model the result was that there was no combination of items that could satisfy the nutritional requirements; the limited amount of food items was attributed to this result [10].

Even if the minimum wage is higher than the cost of the essential BFB, when other factors such as underemployment, poverty line and nutritional needs of the population are taken into consideration it is clear that the current BFB is not adequate for the majority of the population. Taking all these factors into account, the main goal of this study is to determine what items should be present in the Honduran BFB so that nutritional requirements are met at the lowest cost possible using an optimization model.

\section{METHODOLOGY}

\section{A. Linear Programming}

Linear programming consists in the optimization of a linear function that is dependent on linear constraints that aim to either maximize or minimize an objective that depends on decision variables; a linear program is a useful engineering tool because it offers a procedure that guarantees an optimal solution if there is one. Integer linear programming models restrict the decision variables to integers and a variety of them exist such as binary models that restrict the variables to 0 and 1 ; the formulation is similar to that of regular linear programs [11]. For the purposes of this study the aforementioned variation was used.

Linear programming can be used in many fields of study and that includes nutrition. Ferguson, Darmon, Briend and Premachandra developed food based dietary guidelines using linear programming analysis in four different phases for Malawian children; the dietary guidelines that were formulated resembled the populations mean dietary pattern using constraints that assured that the nutrient recommendations were 
met [12]. Parlesak et al., developed a cost minimized nutritionally adequate health promoting food basket; their approach in comparison to Ferguson et al, was to develop 5 different BFB depending on 5 main constraints such as cultural acceptability, nutritionally adequate, health promoting and combination of various constraints [13]. Levesque, Delisle and Agueh also used linear programming to develop a food guide in Benin and used two main constraints which were recommended nutrient intakes and dietary guidelines for the prevention of chronic disease; they determined the optimal number of servings of foods according to food groups [14]. The constraints of each one of these researchers' models are similar and thus will serve as a starting point for a model that determines the Honduran BFB.

Two models were created, one that considers nutritional requirements and suggested portions per food group and a second one that considers nutritional requirements and a balanced diet. For both models three sets of repetitions allowed per food item were tested.

\section{B. Food items}

A total of 240 food items were considered in the initial stages of the study; these were obtained from a list of "basic basket items exempt from sales tax" [15]. Only 165 items remained for the final model due to lack of nutritional information on the other 75 .

Final items were divided in 9 food groups in accordance to the "SMAE" [16]. Some of the items considered with their respective food group can be observed in table \#1.

TABLE I

FOOD ITEMS CONSIDERED BY FOOD GROUP

\begin{tabular}{|c|c|}
\hline Food Group & Item \\
\hline Foods of animal origin - low on fat & $\begin{array}{l}\text { 1. Beef steak } \\
\text { 2. Pork steak } \\
\text { क. } \\
\text { 39.Cottage cheese }\end{array}$ \\
\hline Foods of animal origin - high on fat & $\begin{array}{l}\text { 40. Beef rib } \\
\text { 41. Pork rib } \\
\ldots \\
\text { 66. Mortadella }\end{array}$ \\
\hline Cereals, grains and tubers & $\begin{array}{l}\text { 67. Potato } \\
\text { 68.Cassava } \\
\text { \%. } \\
\text { 97. Oats } \\
\end{array}$ \\
\hline Legumes & $\begin{array}{l}\text { 98. Red beans } \\
\text { 99. Soy } \\
\text { 100. Soy flour }\end{array}$ \\
\hline Fruits & $\begin{array}{l}\text { 101. Banana } \\
\text { 102.Pineapple } \\
\ldots \\
\text { 126. Tamarind }\end{array}$ \\
\hline Vegetables & $\begin{array}{l}\text { 127. Tomato } \\
\text { 128. White onion } \\
\ldots \\
\text { 149. Papaya }\end{array}$ \\
\hline Energy free food & $\begin{array}{l}\text { 150. Lemon } \\
\text { 151.Coffee } \\
\ldots \\
\text { 156. Salt }\end{array}$ \\
\hline Sugars without fat & $\begin{array}{l}\text { 157. Brown sugar } \\
\text { 158. White sugar }\end{array}$ \\
\hline
\end{tabular}

\begin{tabular}{|l|l|}
\hline & 159. Honey \\
\hline & 160. Avocado \\
Oils and fats & 161. Oil \\
& $\ldots$ \\
& 165. Lard \\
\hline
\end{tabular}

These items will be considered as part of the decision variables in the model.

Since the goal of the study is to find an affordable BFB, the price of each of the food items considered were obtained through three different sources, the first two being the equivalent of local farmer's market's, and the third a low cost supermarket. It was important to obtain the prices from sources that are accessible to the population that live in poverty or have less economic income.

Another important factor pertaining to the food items was the weight in grams of each of them so that the price per gram could be obtained. Some items are sold by pound so a direct conversion could be made, some others like milk and honey are sold in liters and their density had to be taken into account in the conversion process, finally some items like bread and onions that are sold by unit were weighted in a scale.

\section{Suggested portions, balanced diet and repetition}

Suggested daily portions per food group and per age group were adapted from the "Guide of food and physical activity" [17]. These portions were used in the constraints pertaining to the first model; the suggested portions of an adult can be seen in table \#2.

TABLE II

SUGGESTED DAILY PORTIONS PER FOOD GROUP

\begin{tabular}{|l|c|c|}
\hline \multicolumn{1}{|c|}{ Food Group } & Minimum & Maximum \\
\hline Foods of animal origin - low on fat & 3 & 4 \\
\hline Foods of animal origin - high on fat & 3 & 4 \\
\hline Cereals, grains and tubers & 8 & 9 \\
\hline Legumes & 2 & 4 \\
\hline Fruits & 3 & 4 \\
\hline Vegetable & 3 & 4 \\
\hline Energy free food & 1 & 1 \\
\hline Sugars without fat & 2 & 2 \\
\hline Oils and fats & 4 & 5 \\
\hline
\end{tabular}

For the second model a balanced diet was considered, this relates to the practice of having at least one portion out of each food group in every one of the three meals (breakfast, lunch and dinner).

Additional factors taken into consideration were the amount of times a food item could be repeated in a month (three different repetition sets were established based on experience) and if each specific food item was available for each mealtime (i.e. no beef steak for breakfast).

\section{Food composition and Dietary reference intakes}

Food composition and portion sizes for each item were also obtained from the "SMAE" [16] due to lack of this kind of document for Honduras. This information was expressed in grams per recommended portion size and was used to formulate 
the constraints of both mathematical models pertaining to nutrient intake.

Dietary reference intakes (DRI), both recommended dietary allowances and tolerable upper intake levels for the 13 nutrients considered in the model were obtained [18]. A sample of the recommended daily allowances can be seen in table \#3. In total 13 nutrients were considered for the study.

TABLE III

\begin{tabular}{|c|c|c|c|c|c|c|c|}
\hline $\begin{array}{c}\text { Life } \\
\text { Stage } \\
\text { Group }\end{array}$ & $\begin{array}{c}\text { Carb. } \\
(\boldsymbol{g} / \boldsymbol{d})\end{array}$ & $\begin{array}{c}\text { Fiber } \\
(\boldsymbol{g} / \boldsymbol{d})\end{array}$ & $\begin{array}{c}\text { Protein } \\
(\boldsymbol{g} / \boldsymbol{d})\end{array}$ & $\ldots$ & $\begin{array}{c}\text { Sodium } \\
(\boldsymbol{m g} / \boldsymbol{d})\end{array}$ & $\begin{array}{c}\text { Vit. } \boldsymbol{A} \\
(\boldsymbol{\mu g} / \boldsymbol{d})\end{array}$ & $\begin{array}{c}\text { Vit. } \boldsymbol{C} \\
(\boldsymbol{m g} / \boldsymbol{d})\end{array}$ \\
\hline Child & & & & $\ldots$ & & & \\
\hline $4-8 \mathrm{y}$ & 130 & 25 & 19 & $\ldots$ & 1500 & 400 & 25 \\
\hline Teen M & & & & $\ldots$ & & & \\
\hline $14-18$ y & 130 & 38 & 52 & $\ldots$ & 1500 & 900 & 75 \\
\hline Teen F & & & & $\ldots$ & & & \\
\hline $14-18$ y & 130 & 26 & 46 & $\ldots$ & 1500 & 700 & 65 \\
\hline Male & & & & $\ldots$ & & & \\
\hline $19-30$ y & 130 & 38 & 56 & $\ldots$ & 1500 & 900 & 90 \\
\hline Female & & & & $\ldots$ & & & \\
\hline $19-30$ y & 130 & 25 & 46 & $\ldots$ & 1500 & 700 & 75 \\
\hline Pregnant & & & & $\ldots$ & & & \\
\hline $14-18$ y & 175 & 28 & 71 & $\ldots$ & 1500 & 750 & 80 \\
\hline
\end{tabular}

\section{E. Scenarios}

According to the national statistics institute "INE" the average Honduran household has 4.3 members [1]. Six scenarios were established for each of the two models as follows:

- Model 1 - nutrient requirement and suggested daily portions

- Scenario 1: one male teen, one female teen, one male adult and one female adult.

- Scenario 2: one male teen, one female teen, one male adult and one pregnant female.

- Scenario 3: one child, one male teen, one male adult and one female adult.

- Scenario 4: one child, one male teen, one male adult and one pregnant female

- Scenario 5: two children, one male adult and one female adult

- Scenario 6: two children, one male adult and one pregnant female

- Model 2 - nutrient requirement and balanced diet

○ The same 6 scenarios were done for the second model.

Subjects were chosen based on who had the highest nutrient intake so that the model could work with higher requirements. Each scenario for each model was solved for each of the three-monthly repetition sets established making a total of 36 runs.

\section{F. Open Solver}

Due to the high number of variables that are considered in the model the OpenSolver add-in was used to solve each of the models and their scenarios [19].

\section{MATHEMATICAL MODEL}

Every linear programming model consists of three basic components: decision variables that are meant to be determined, the objective function that is going to be optimized by minimizing or maximizing and constraints that the solution has to uphold [20].

\section{A. Nomenclature and parameters}

$\boldsymbol{i}=$ represents all the food items considered in the study which are $165(1, \ldots, 165)$. The food items $i$ that belong to each food groups are the following:

$$
\begin{array}{ll}
\text { - } & \mathrm{AO}-\mathrm{LF}=\{1, \ldots, 39\} \\
\text { - } & \mathrm{AO}-\mathrm{HF}=\{40, \ldots, 66\} \\
\text { - } & \mathrm{CGT}=\{67, \ldots, 97\} \\
\text { - } & \mathrm{LG}=\{98,99,100\} \\
\text { - } & \mathrm{FR}=\{101, \ldots, 126\} \\
\text { - } & \mathrm{VG}=\{127, \ldots, 149\} \\
\text { - } & \mathrm{EF}=\{150, \ldots, 156\} \\
\text { - } & \mathrm{SG}=\{157, \ldots, 159\} \\
\text { - } & \mathrm{OL}=\{160, \ldots, 165\}
\end{array}
$$

$\boldsymbol{j}=$ represents the three mealtimes in a day; breakfast, lunch and dinner $(1,2,3)$

$\boldsymbol{k}=$ represents the days of the week $(1, \ldots, 7)$

$\boldsymbol{l}=$ represents the number of weeks considered $(1, \ldots, 4)$

$\boldsymbol{m}=$ represents the subjects considered in the study $(1, \ldots, 6)$ as shown in table \#4.

TABLE IV

SUBJECTS CONSIDERED IN THE STUDY

\begin{tabular}{|c|c|}
\hline$\#$ & Subject \\
\hline 1 & Male teen \\
\hline 2 & Female teen \\
\hline 3 & Male adult \\
\hline 4 & Female adult \\
\hline 5 & Pregnant Female \\
\hline 6 & Child \\
\hline
\end{tabular}

The subject $m$ that belong to each scenario are the following:

- Scenario $1=\{1,2,3,4\}$

- Scenario $2=\{1,2,3,5\}$

- Scenario $3=\{1,3,4,6\}$

- Scenario $4=\{1,3,4,5\}$

- Scenario $5=\{6,6,3,4\}$

- Scenario $6=\{6,6,3,5\}$ 
$\boldsymbol{n}=$ represents the nutrients considered for the study which are 13 in total $(1, \ldots, 13)$.

$\boldsymbol{o}=$ represents the food groups in which the food items were classified as stated above $(1, \ldots, 9)$.

$\boldsymbol{p}=$ represents the scenarios in which the persons were classified as stated above $(1, \ldots, 6)$.

The parameters that were used to construct each model are the following:

- $\quad N_{m n}$ : minimum requirement of nutrient $n$ for person $m$

- $\quad \boldsymbol{N M}_{m n}$ : maximum requirement of nutrient $n$ for person $m$

- $\quad C_{n i}$ : content of nutrient $n$ per portion of food item $i$

- $\quad \boldsymbol{L}_{i}$ : price per gram of food item $i$

- $W_{i}$ : weight of a portion of food item $i$

- PMinom: minimum number of portions of food group $o$ for person $m$

- PMaxom: maximum number of portions of food group $o$ for person $m$

- $\quad \boldsymbol{H}_{i j:} 1$ if food item $i$ is available for mealtime $j$

- $M_{i}$ : number of repetitions of food item $i$ allowed

- $\boldsymbol{G A}_{\boldsymbol{o}}$ : food group $o$

- $S_{p}$ : scenario $p$

- $\boldsymbol{P}$ : number of people in the scenario

\section{B. Decision variables}

Both models contain the same decision variables, it was decided that the models would consider 4 weeks for each of the scenarios given and that it would be binary. The variable was defined as follows:

$\boldsymbol{X}_{i j k l}: 1$ if food item $i$ is assigned to mealtime $j$ in the day $k$ of the week $l ; 0$ on the contrary

A total of 13,860 variables are considered for each model.

\section{Objective Function}

The main goal of the study is to determine a BFB while minimizing the total cost, thus the objective function was defined as follows:

$\operatorname{Min} Z=\sum_{i=1}^{165} \sum_{j=1}^{3} \sum_{k=1}^{7} \sum_{l=1}^{4} X_{i j k l} L_{i} W_{i} P$

\section{Constraints}

The model has to comply with diverse constraints so that the solution is acceptable, the constraints will be divided in three groups; general constraints that apply to both models, suggested daily portions for the first model only and balanced diet for the second model only.

General constraints:

Minimum amount of each of the required nutrients, this constraint is valid for each day, each week and each one of the nutrients. This constraint varied according to the scenario that was being analyzed. 364 constraints are represented in the following group:

$\sum_{i=1}^{156} \sum_{j=1}^{3} X_{i j k l} H_{i j} C_{n i} \geq \sum_{m \in S_{p}} N_{n m} \forall k ; l ; n$

Maximum amount of each of the required nutrients, this constraint is valid for each day, each week and each one of the nutrients. This constraint varied according to the scenario that was being analyzed. 364 constraints are represented in the following group:

$\sum_{i=1}^{156} \sum_{j=1}^{3} X_{i j k l} H_{i j} C_{n i} \leq \sum_{m \in S_{p}} N M_{n m} \forall k ; l ; n$

Maximum amount repetitions of each food item in the four weeks that are considered in the models. It's worth noting that 3 different set of repetitions were tested for each scenario. 165 constraints are represented in the following group:

$\sum_{j=1}^{4} \sum_{k=1}^{7} \sum_{l=1}^{4} X_{i j k l} \leq M_{i} \forall i$

The decision variables can only adopt a 1 or a 0 , making it a binary model. 13,860 constraints are represented in the following group:

$X_{i j k l}=b i n$

Model 1 exclusive constraints:

Minimum amount of portions for each of the food groups, this constraint is valid for each day, each week and each one the food groups. This constraint varied according to the scenario that was being analyzed. 252 constraints are represented in the following group:

$\sum_{i \in G A_{o}} \sum_{j=1}^{3} X_{i j k l} \geq 0.8 \sum_{m \in S_{p}} \operatorname{PMin}_{o m} P \forall k ; l ; o$

Maximum amount of portions for each of the food groups, this constraint is valid for each day, each week and each one the food groups. This constraint varied according to the scenario that was being analyzed. 252 constraints are represented in the following group:

$$
\sum_{i \in G A_{o}} \sum_{j=1}^{3} X_{i j k l} \leq 1.2 \sum_{m \in S_{p}} \operatorname{PMax}_{o m} P \forall k ; l ; o
$$


As Donati et al. did in their study to give the model some flexibility a tolerance was given to both the minimum and maximum portions [21].

Model \#2 exclusive constraints:

Balanced diet constraint, each mealtime must have at least one item of each food group, this constraint is valid for each mealtime, each day, each week and each one the food groups; it's worth noting that food group 1 and 2 where considered as one in this constraint since both are items from animal origin. 810 constraints are represented in the following group:

$$
\sum_{i \in G A_{o}} X_{i j k l} \geq 1 \forall j ; k ; l ; o
$$

The total number of constraints for each model are the following:

- Model 1: 15,257 constraints

- Model 2: 15,563 constraints

\section{RESULTS}

\section{A. Model 1- Suggested portions per day (scenario 1)}

Results from the first scenario of model 1 can be observed in figure \#1.

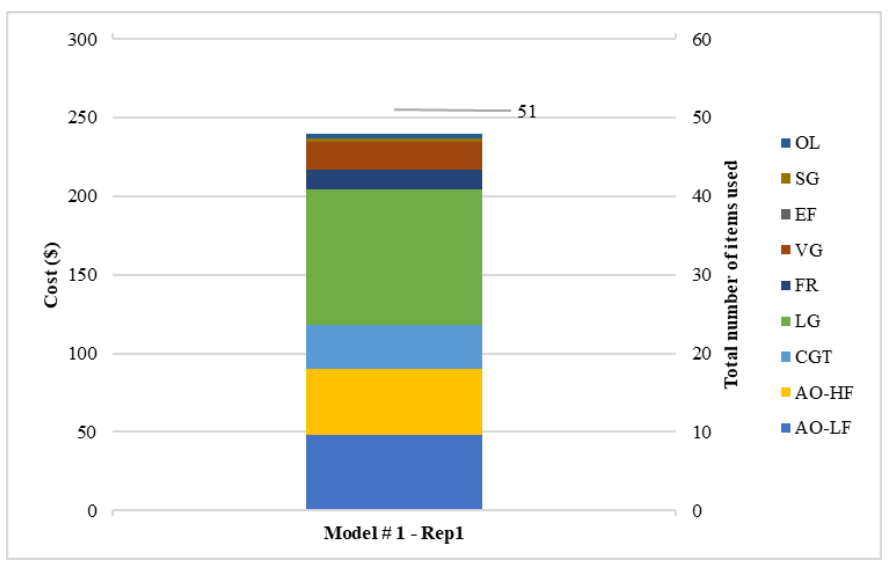

Fig. 1 Cost of selected food items and total items selected

Total cost of the BFB was found at $\$ 239.73$, the biggest contributor to price was the legumes group with $\$ 86.15$. Compared to the current BFB it presents a global increase of $\$ 63.72$, nevertheless this combination of items can fulfill the daily nutritional requirements and the current one cannot. A total of 51 food items were selected from the 165 available in the model, this represents an increase from the 30 that are available in the essential BFB but can also be attributed to a high amount of repeatability allowed in the month. The detail of how many items belong to each food group can be seen in figure \#2.

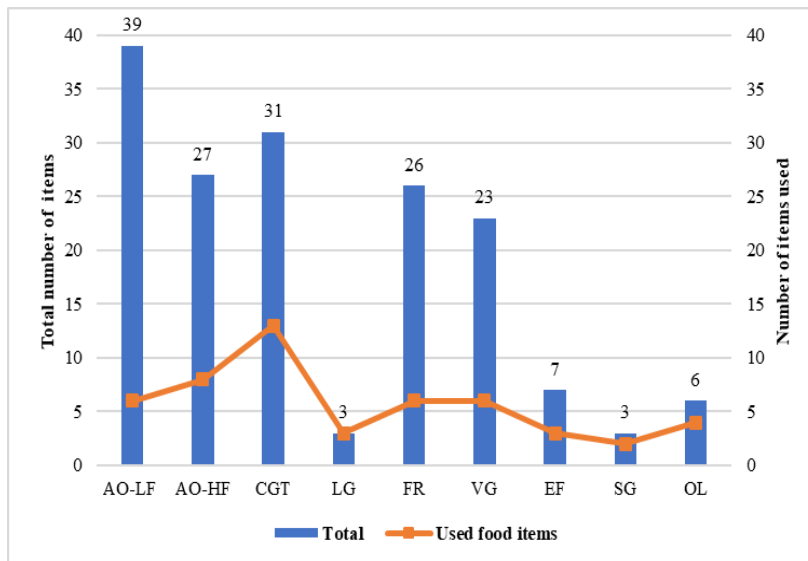

Fig. 2 Used food items in model \#1, scenario 1, first set of monthly repetitions

The highest count of used food items come from the cereals, grains and tubers food group with a total of 13 items out of the 31 available being used. The legumes were used in their totality due to the fact that only three items are available in this group; their high price in the overall cost happens because, since they are limited in number, they are allowed to be repeated many more times in a month than other groups that have more variety. They are also a very good source of phosphorus and potassium and since the model has to fulfill nutritional requirements and other food groups are lacking in this two components it assigns them whenever possible. Other groups such as fruits and vegetables only use 6 items each when they have 26 and 23 total items respectively; these items include banana, pineapple, orange, broccoli, beets and onion amongst others. The low count arises from the repetitions allowed in a month and their low cost compared to other items such as strawberry or eggplant that are not as attractive to the model.

\section{B. Model \# 1- Suggested portions per day (all scenarios)}

Further analysis was deemed to be necessary and thus a comparison was made between all 6 scenarios of model 1. Said scenarios were done by using all 3 sets of repetitions allowed for a total of 18 runs. The results of this comparison can be observed in figure \#3.

Scenarios 2, 4 and 6 include a pregnant female, an increase in food items can be seen, especially in scenario 2. Scenario 2 consists of two teenagers (male and female), a male adult and a pregnant female; this combination is one of the most demanding regarding both nutrient intake and recommended portions for both the teenagers and the pregnant female. When compared to scenario 6 where the teenagers are replaced with two children a decrease can be observed, this is due to the lower nutrient and portion requirements for both children.

Regarding cost, the models that present the higher cost across the board are the ones that contain the pregnant female when compared to their counterparts that include a female adult. The highest cost is seen in scenario 2 for the third set of repetition constraints with a total of $\$ 252.60$ which is $\$ 76.59$ 


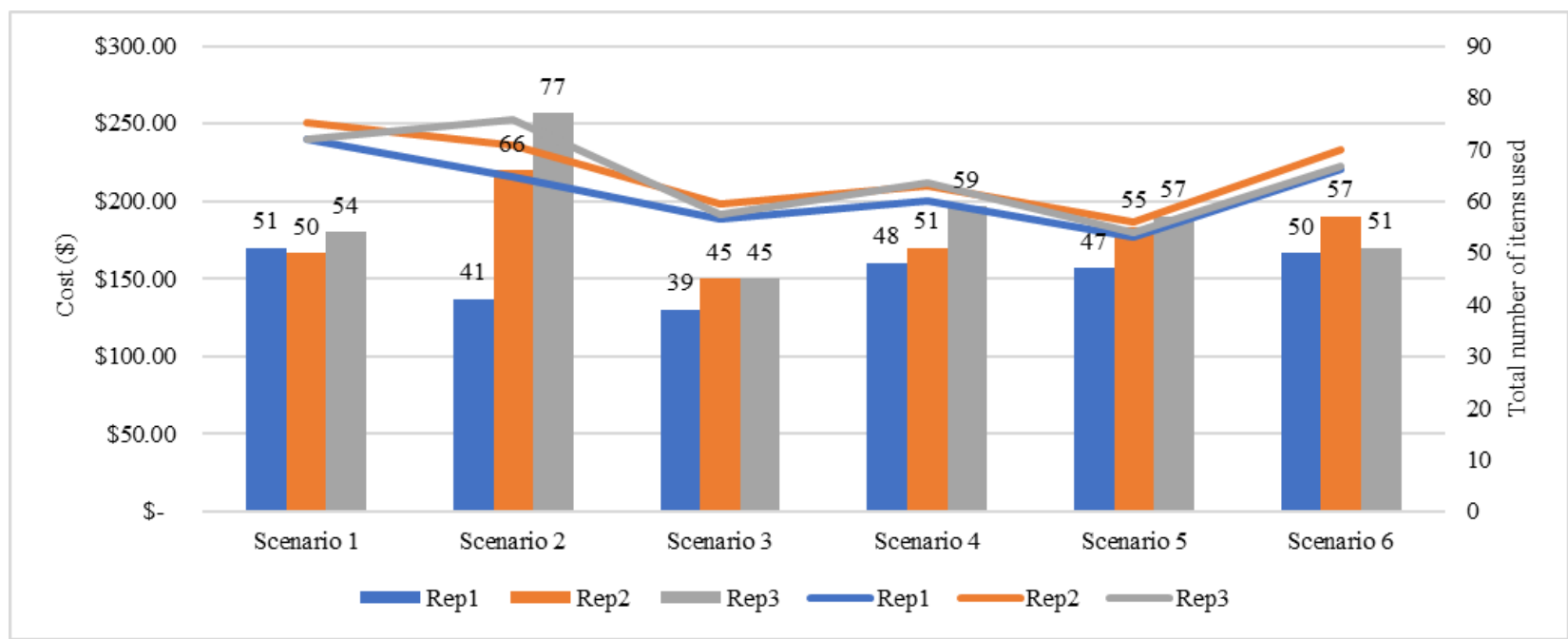

Fig. 3 Used food items vs. cost in all scenarios for model \#1

more expensive than the current BFB. The only scenario that came close to the current price was scenario 5 with the first set of repetition constraints with a cost of $\$ 177.08$; the key difference is that it used a total of 47 food items versus the 30 currently available and it fulfills nutritional requirements.

\section{Model 2-Balanced diet (Scenario 1)}

Results from the first scenario of model 2 can be observed in figure \#4.

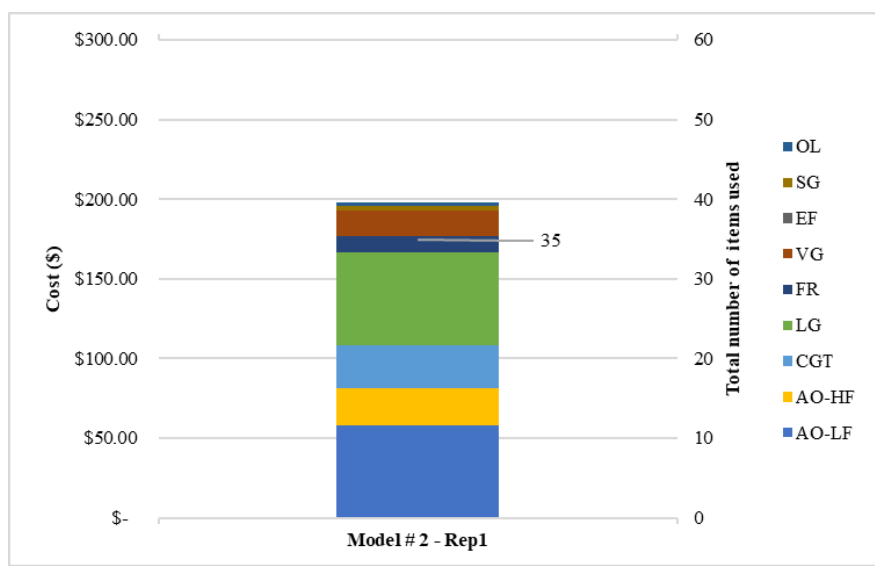

Fig.4 Cost of selected food items and total items selected

Total cost of the BFB was found at $\$ 198.02$, the biggest contributor to price was the legumes group with $\$ 58.34$. Compared to the current BFB it presents a global increase of $\$ 22.01$, nevertheless this combination of items can fulfill the daily nutritional requirements and the current one cannot. A total of 35 food items were selected from the 165 available in the model, this represent an increase from the 30 that are available in the essential BFB but only by 5 items.
The low count compared to model \#1 can be attributed to the difference in constraints used. The balanced diet constraint only states that each food group must be present at least once a day for each mealtime; the suggested portions constraint of the first model asks for a minimum of portions daily. The detail of how many items belong to each food group can be seen in figure \#5.

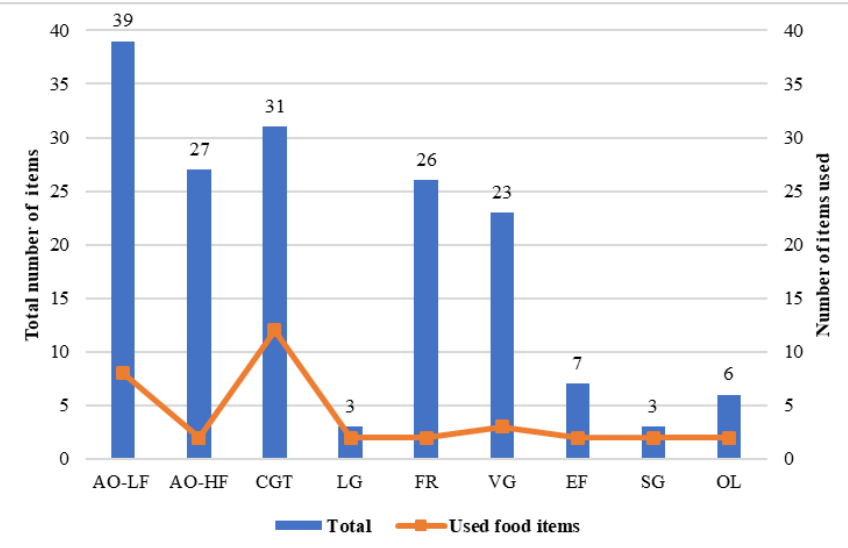

Fig. 5 Used food items in model \#2, scenario 1, first set of monthly repetitions

A very low count of each of the food groups can be observed with some being as low as 2 items out of 26 for fruits or 3 vegetables out of 23 available for example, as stated above this behavior pertains to the constraints of the model.

C. Model 1 and 2 comparisons.

Considering the varying results of both models a side by side comparison was made and can be seen in figure \# 6 . 


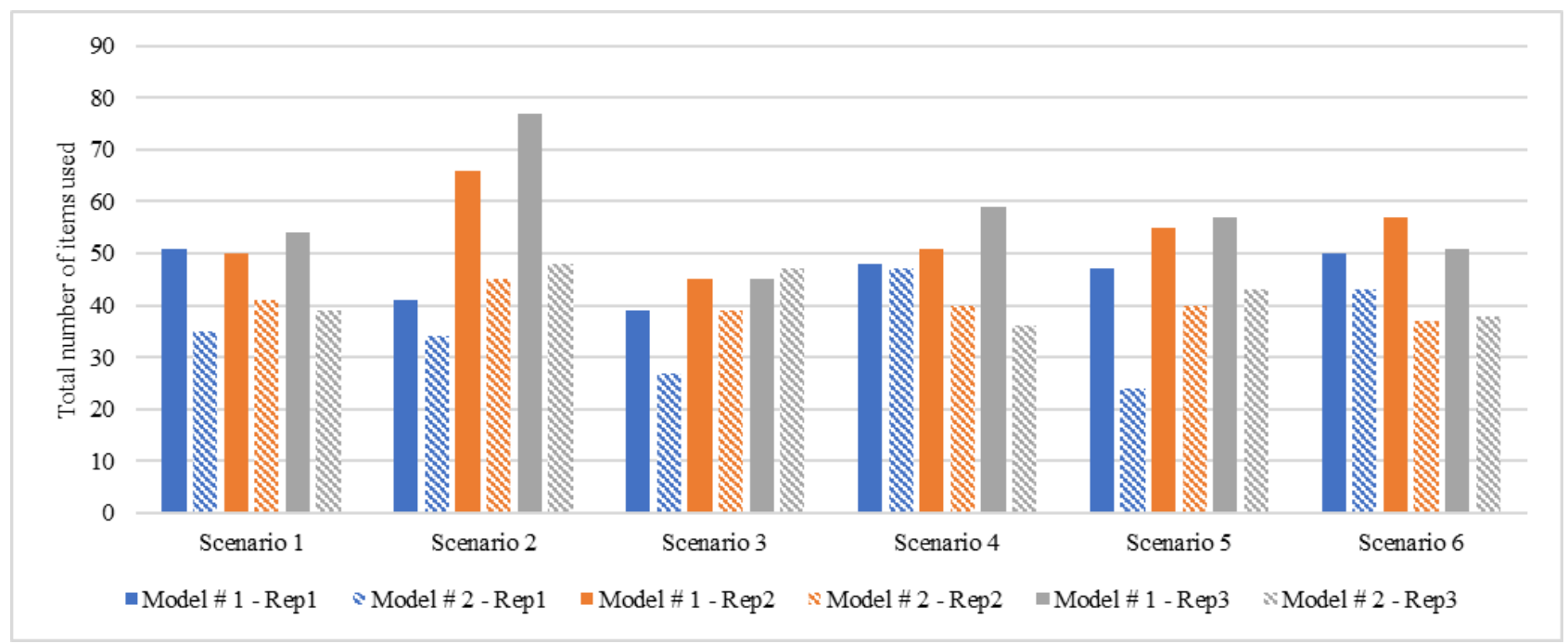

Fig. 6 Used food items in both models for all scenarios and allowed repetitions

Results from model 1 were higher in terms of food items that were used across almost every scenario with the exception being scenario 3 for the third set of repetitions. This coincides with what was inferred above relating to the constraints that were used in each model. Scenario 2 maintains the highest number of food items. Taking this into account this scenario using the first model was selected to construct the BFB considering it had the higher nutrient requirement and allows for a more varied diet in a month when compared to results from the second model.

\section{Determination of the Basic Food Basket}

Detailed information pertaining to scenario 2 can be observed in figure \#7 and \#8.

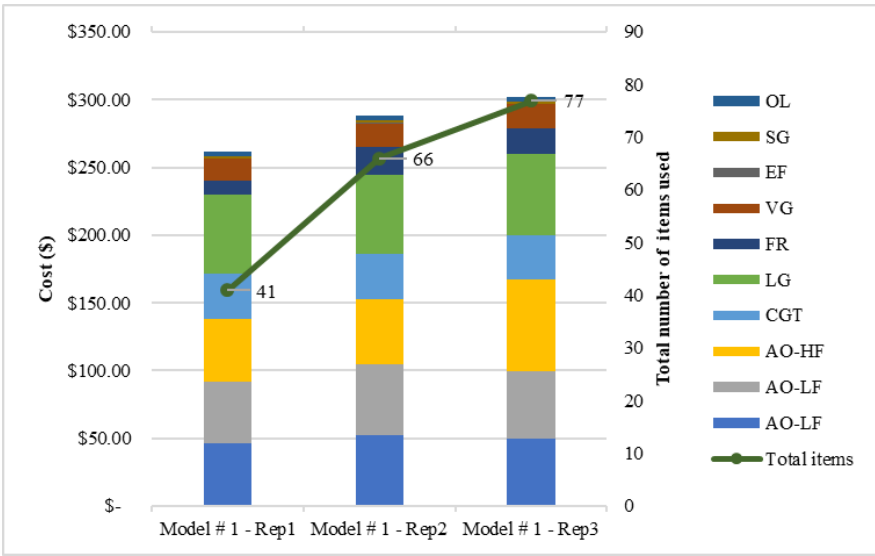

Fig. 7 Cost of selected food items and total items selected for model 1, scenario 2

A clear increase in both cost and total number of food items selected can be seen. Legumes maintain their tendency to represent a high amount of the total cost followed by the items that are of animal origin, both high and low on fat.

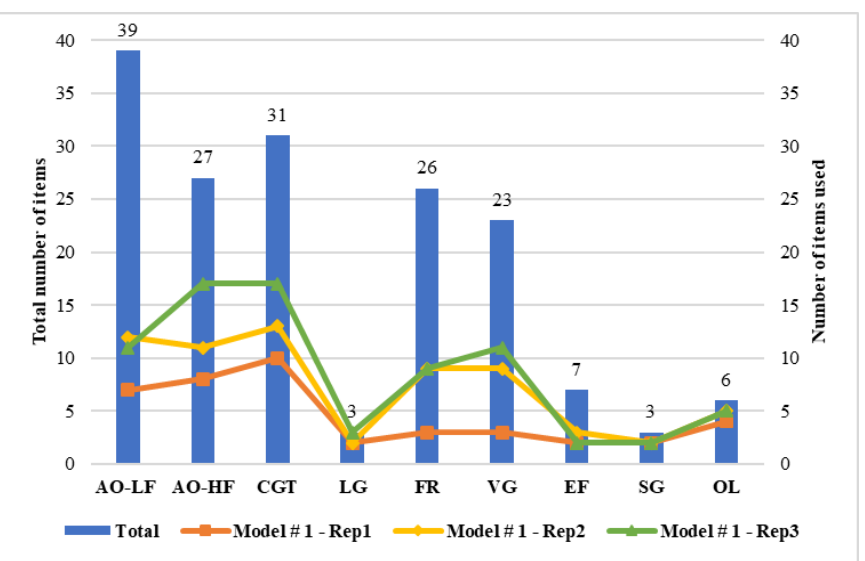

Fig. 8 Used food items in model 1, scenario 2

The number of items per food group for the first set of repetitions have lower values across the board while the ones regarding the third set of repetitions have the highest values. The cereals, grains and tubers represent the highest total count of food items for all three repetition sets. Legumes are utilized in a similar way for all three sets due to the limited amount of total available items in this food group.

The model with the second set of repetitions oscillates between the other two in most cases be it for used items for each food group and cost. Thus, the BFB was determined using this model, scenario and set of repetitions so a clear panorama of a nutrient heavy family can be observed. It's worth noting that the BFB can be determined for all other scenarios, in the same way. Final BFB is shown in table \#5 below. 
TABLE V

BASIC FOOD BASKET (SCENARIO 2)

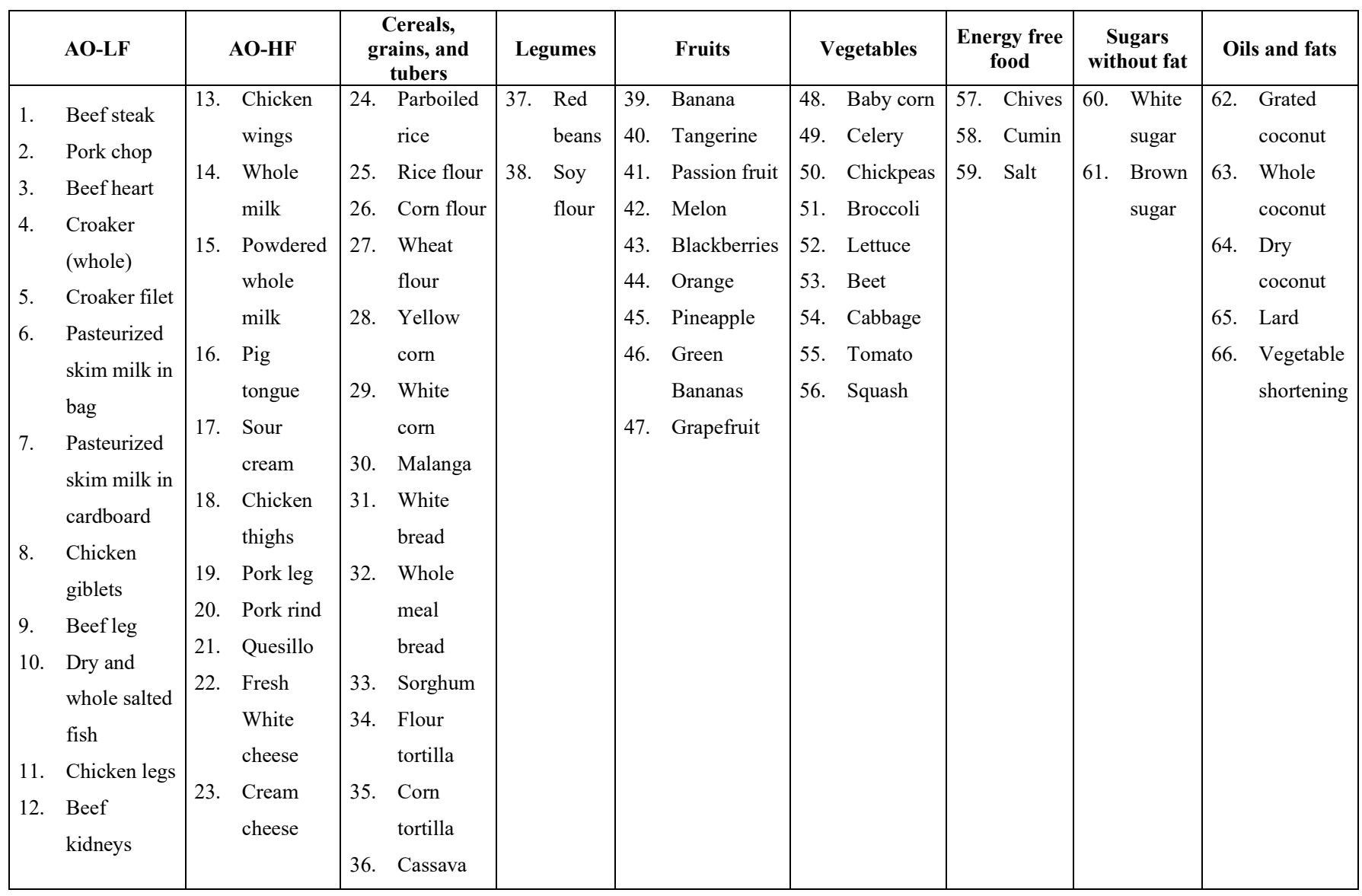

The model not only determined the BFB as shown above. The 66 items presented were distributed across four weeks for three mealtimes each day while fulfilling the constraints that some items are not available for some mealtimes like chicken giblets which cannot be eaten at breakfast, only lunch and dinner. The food distribution was defined in a way that if a corn tortilla was assigned to dinner on a Monday all the subjects considered in the study would eat the same item, this was done to avoid scenarios that each member of the family would eat different foods each day.

\section{CONCLUSION}

A Basic Food Basket was successfully determined utilizing linear programming across a varied range of scenarios. Total cost of the BFB ascends to $\$ 235.86$ which represents a $34 \%$ increase when compared to the current essential BFB, nevertheless the one obtained allows for more variety of foods and fulfiment of nutritional requirements. The cost represents $58 \%$ of the estimated minimum wage without considering factors such as the high underemployment rates, poverty rates and other costs that are necessary for daily living such as medical expenses, public services, school supplies amongst others. When combining every factor, it can be inferred that the majority of the population in the country cannot meet basic nutritional requirements with the current state of employment.

\section{ACKNOWLEDGMENT}

We would like to thank Mendel Nelson who provided a listening ear when some issues arose during the development of this research; his time and advice proved to be highly useful.

\section{REFERENCES}

[1] INE. (2018). Indicadores Cifras País 2018. Retrieved from INE Instituto Nacional de Estadística: https://www.ine.gob.hn/V3/imagdoc/2019/09/cifras-de-pais-2018.pdfM. King, B. Zhu, and S. Tang, "Optimal path planning," Mobile Robots, vol. 8, no. 2, pp. 520-531, March 2001.

[2] Secretaría de Trabajo y Seguridad Social. (2020). Tabla de Salario Mínimo 2020 y Tabla del Bono Educativo 2020. Retrieved from Secretaría de Trabajo y Seguridad Social: http://www.trabajo.gob.hn/wpcontent/uploads/2020/01/Tabla-Salario-Minimo-2020.pdfM. King and B. Zhu, "Gaming strategies," in Path Planning to the West, vol. II, S. Tang and M. King, Eds. Xian: Jiaoda Press, 1998, pp. 158-176.

[3] Senkrua, A. (2018). A Review Paper on Visible and Invisible. Chiang Mai University Journal of Economics, 83-99.

[4] Feldman, D. C. (1996). The Nature, Antecedents and Consequences of Underemployment. Journal of Management, 385-407. 
[5] World Food Programme. (n.d.). Honduras. Retrieved from World Food Programme: https://www1.wfp.org/countries/honduras

[6] CDC. (2017, January 25). Refugee Health Profiles. Retrieved from Centers for Disease Control and Prevention: https://www.cdc.gov/immigrantrefugeehealth/profiles/centralamerican/health-information/nutrition/index.html

[7] FAO and PAHO. (2017). Panorama of Food and Nutrition Security in Latin America and the Caribbean. Santiago de Chile.

[8] UN. (1981). Seminario sobra Pobreza y Grado de Satisfacción de las Necesidades Básicas en el Istmo Centroamericano. Ciudad de México.

[9] Secretaría de Desarrollo Económico. (n.d.). Nuevo modelo de la Canasta Básica Familiar. Tegucigalpa.

[10]Montenegro, D., \& Mendez, D. (2020). Integer Linear Programming for a Balanced Diet in Honduras. Unpublished.

[11]Grasman, S. E., Gosavi, A., \& McConky, K. (2016). Operations Research. Huntsville: Engineering Management Handbook.

[12]Elaine L. Ferguson, N. D. (2004). Food-Based Dietary Guidelines Can Be Developed and Tested Using Linear Programming Analysis. American Society for Nutritional Sciences., 951-957.

[13]Alexandr Parlesak, I. T. (2016). Use of Linear Programming to Develop Cost-Minimized Nutritionally Adequate HealthPromoting Food Baskets. PLoS ONE 11, 1-19.
[14]Sarah Levesque, H. D. (2014). Contribution to the development of a food guide in Benin: linear programming for the optimization of local diets. Public Health Nutrition, 622-631.

[15]Secretaría de Finanzas. (n.d.). Ley del impuesto sobre ventas texto consolidado. Tegucigalpa.

[16]Lizaur, P., \& Bertha, A. (2014). SMAE: SISTEMA MEXICANO DE ALIMENTOS EQUIVALENTES. FNS.

[17]Conacyt. (2014). Guías alimentarias y de actividad física. Ciudad de México: Intersistemas.

[18]J. Dwyer, N. A. (2016). Dietary References: US. Encyclopedia of Food and Health, 418-431.

[19]Klatte, D. L.-J. (2011). OpenSolver - An Open Source Add-in to Solve Linear and Integer Progammes in Excel. Operations Research Proceedings, 401-406.

[20]Taha, H. A. (2017). Investigación de operaciones. Pearson.

[21]Donati, M., Menozzi, D., Zighetti, C., Rosi, A., Zinetti, A., \& Scazzina, F. (2016). Towards a sustainable diet combining economic, environmental and nutritional objectives. Appetite, 48-57. 